\title{
49
}

\section{Improving construction information communications: A development framework}

\author{
A.Grilo \\ PhD Candidate, University of Salford \\ Bridgewater Building, Salford, M5 4WT, UK, e-mail: \\ a.griloemail.telepac.pt

\section{L.T. Almeida} \\ Professor of Instituto Superior Técnico \\ Av. Rovisco Pais, 1000 Lisboa, Portugal
}

\begin{abstract}
Electronic data exchange will be one of the key element for raising the low productivity levels of construction projects. This paper advocates the use Information and Communication Technologies (ICT) for improving construction communications, and describes the business and technical objectives of a framework which aims to create, implement, test and evaluate an EDI-based communication infrastructure between the various parties involved in the manufacturing process of construction. The infrastructure explores the potential of both STEP and EDIFACT, and is to automate the ordering, delivery, invoicing and payment process of construction systems, equipment and services in a supply chain whose members are on very different levels regarding ICT.
\end{abstract}

Keywords

Construction, virtual enterprises, EDI, EDIFACT, STEP, interorganisational information systems. 


\section{INTRODUCTION}

The construction process is characterised by temporary networks of "co-operating" organisations also designated as virtual enterprises. The coordination and control within these virtual enterprises is far from efficient. Thus, construction industry productivity is lagging behind manufacturing and service industries. One of the developments that may improve productivity is the deployment of computerised interorganisational information systems between the various parties. Indeed, the establishment of effective communication and logistics processes involving designers, contractors, subcontractors and material suppliers, is perceived by many construction researchers and practitioners as an area which deserves further research and development.

ICT systems have long been used by firms on manufacturing and service industries, specially on banking, automotive and retailing industries. Research studies have shown that there is scarce use of ICT systems by firms involved on construction projects. Electronic Data Interchange, using EDIFACT standards for commercial information and product data exchange using STEP are two available technologies that are useful for building a ICT infrastructure for construction virtual enterprises.

This paper starts by describing the potentialities for the development of an ICT infrastructure for construction virtual enterprises and the technologies available for building the infrastructure. It follows by describing the business and technical objectives, as well as the predicted industrial impact of a development framework which aims to create, implement, test and evaluate an EDI-based communication infrastructure between the various parties involved in the construction process.

\section{THE IMPORTANCE OF INFORMATION COMMUNICATIONS IN CONSTRUCTION}

There is a well established consensus about the low productivity on the construction industry, specially when compared with other industries and even that the gap is increasing (Atkin and Pothecary, 1994; Latham, 1994). The construction industry is a mature industry and in the last few years, due economical recession and globalisation, there has been an increase of the competition within the industry. Moreover, products are becoming more complex and clients more demanding requiring cheaper, with lower lead times, and with higher quality products (Atkin and Pothecary, 1994)

The construction process is characterised by temporary networks of "co-operating " organisations (Cherns and Bryant, 1983). Indeed, for each project a virtual enterprise is assembled in which architects, engineers, specialist designers, contractors, subcontractors, suppliers, etc. organisations are brought together in 
order to build the product. In a traditional and simplistic way, construction projects are split into the design and construction phases. The architect is the project leader, developing a design and design management responsibility and devolving a role for specialist design and management functions to engineers, surveyors and the like. On the construction phase a main contractor is responsible for the completion of the entire project and procures the services of specialist firms. These specialist firms are subcontractors who carry out work on-site, and suppliers who manufacture products off-site and deliver them as needed.

In order to improve productivity, current developments in the sector are increasingly focusing on more effective management of the construction virtual enterprise, through developments such as design and build, multi-disciplinary design and project management, and inter-organisational information systems. Good project management must nowadays pay as much attention to the production as to the overall information flow. Increases of $15 \%$ to $20 \%$ in the performance of projects (cost, quality, speed, customers satisfaction) may be accomplished if the information flows within the virtual enterprise are carefully addressed and improved (Latham, 1994). However, the short-term duration of construction projects, the non-repetitive nature of the industry, and the geographical distance between headquarters of the companies and the construction sites which have a limited existence in time and space, makes it difficult to have timely, adequate, and accurate information for project coordination and control activities (Atkin and Pothecary, 1994). Moreover, little attention has been given to the establishment of effective communication and logistics processes involving designers, contractors, subcontractors and material suppliers.

Information and Communication Technologies (ICT) have been a major enabler and facilitator of the effective management of the interdependencies and information flows of the banking, manufacturing and retailing industries. Indeed, a contrasting difference between manufacturing/service virtual enterprises and construction virtual enterprises is that the former are enabled and supported by wide ICT infrastructures. Construction projects are characterised by the elaboration by the various parties of large amounts of computer generated information, that circulates and is exchanged on a paper format (Thorpe and Murray, 1996). Thus, there is wide scope for the development of an ICT infrastructure that allows closer working between the various parties involved on construction projects, i.e. between designers and contractors; contractors and subcontractors, material suppliers, builders merchants and/or plant hirers. An ICT infrastructure imply that information flows on construction projects would be partially automated and aiming at a paperless working place. Technical information, i.e. drawings, technical advice, etc.; management and control information, i.e. project planning, progress reports, delivery schedules, etc.; and commercial information like orders, $\mathrm{BoQ}$, tenders, invoices, valuations, etc. could flow seamless through ICT infrastructure between the parties involved in the virtual enterprise (DOE, 1995). 


\section{ICT INFRASTRUCTURE AVAILABLE FOR CONSTRUCTION FIRMS}

\section{1. -Electronic Data Interchange (EDI)}

EDI is the electronic transfer from computer to computer of commercial and administrative information using an agreed standard to structure the transaction or message (Emmelhainz, 1993). The essence of EDI is the structured data transfer, which allows information to flow from one computer to another without manual intervention.

The development of EDI is dependent on (Akintoye and McKellar, 1997): Transaction message standards; Translation software which interface between the application software and the message standards; Telecommunications to transmit the structured data from one computer to another.

The main benefits from the use of EDI by construction firms are envisaged to be (Baldwin et al, 1995):

- reductions in paper handling;

- shifting personnel work from no-added value tasks to more relevant work;

- elimination of data re-keying;

- dramatic reduction in data processing errors;

- savings in communication costs;

- increased production efficiency;

- reduction in supply and distribution costs (through a better supply chain management);

- more flexibility and responsiveness;

- shorter communication cycle time.

The international standards for commercial data is based on the EDIFACT (Electronic Data Interchange for Administration, Commerce and Transport, ISO 9735). This standard defines a significant number of messages for different applications (e.g. order, delivery, inquiry etc.) which reduces the communication overhead for the information exchange between companies. Today there exist more than 40 standard messages and more than 150 messages are under development.

Table 1 indicates some of the EDIFACT messages relevant for the construction industry. Two of them are related directly to the building invoice, the rest is without special emphasis to the industry in question. Subsets of the above listed EDIFACT messages which are dealing with building and construction industry are not available by now. 


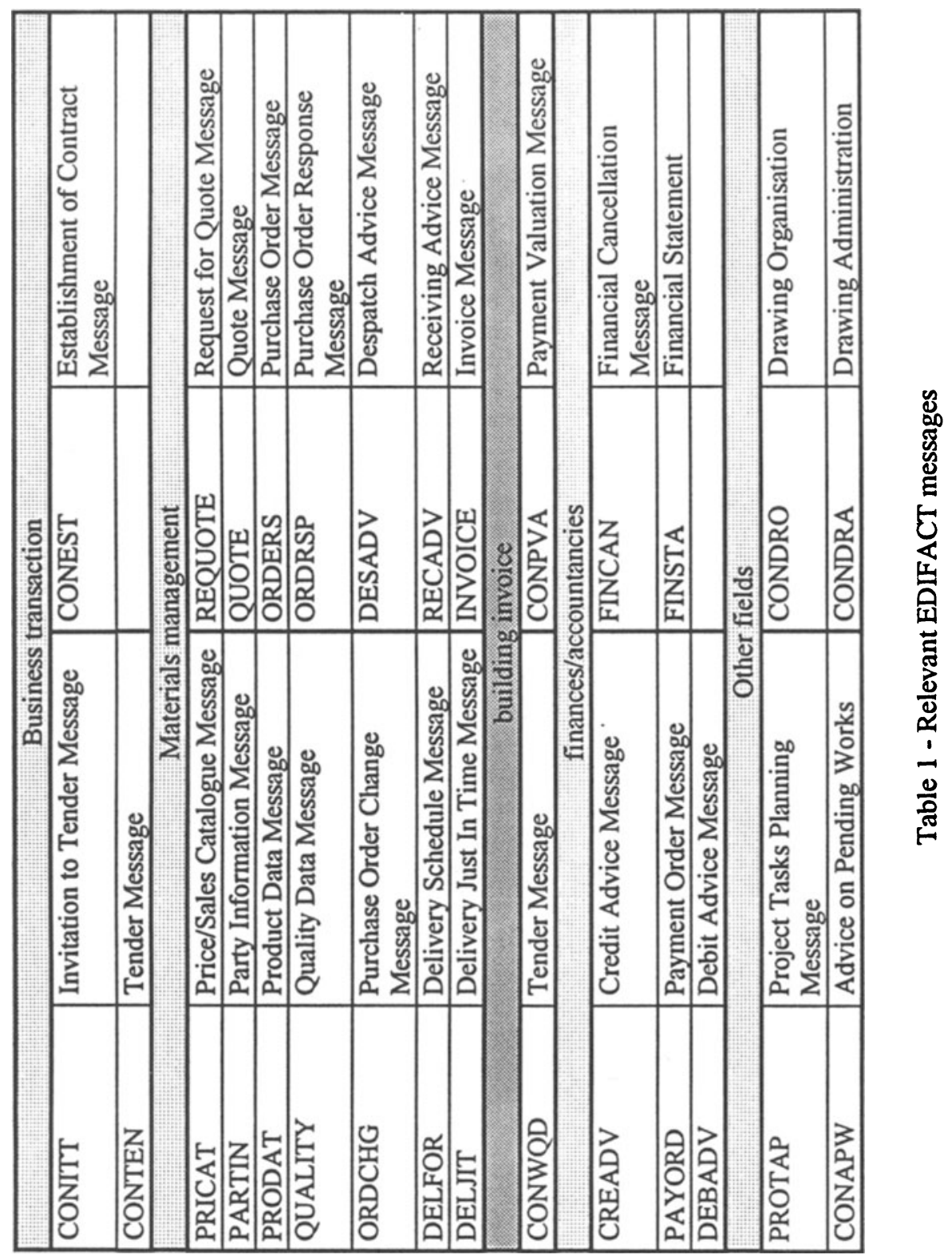


Several research studies have shown that there is scarce use of EDI by construction firms. In the UK, studies show that the only firms using EDI are builders merchants, which are electronically linked with some material suppliers and manufacturers (Baldwin et al, 1995; Akintoye and McKellar, 1997). The main reasons for the low dissemination of EDI on the construction industry are the industry's fragmentation; fragmented clients; unique nature of each project; sheer complexity of the construction information flows; and lack of IT (DOE, 1995).

\section{2. - Product Data Exchange}

EDIFACT has been developed in support of administration and commercial activities. In construction industry, we are not dealing with standard of-the-shelf products in the majority of cases. Ordering of "make-to-order" products such as dormer windows, conservatories, boilers, etc. accompanies significant level of engineering information and is normally accompanied by an intense data-exchange process on design refinement. The international standard which supports the exchange of product data for manufacturing is STEP (STandard for Exchange of Product model data).

Although there has been sporadic interest and involvement in STEP from within the construction sector reaching back to the mid 1980's, the current level of involvement began to take shape with an Application Protocol Planning Project for Building and Construction (APPP-BC) that was formally initiated in October 1993. The APPP identified nested families of models required to represent information from building construction industries. The AP's currently under development within the building construction group are as follows (Katranuschkov and Scherer, 1996):

- AP225 - Building Elements Using Explicit Shape Representation (ISO 1995). AP225 is aimed at representing buildings as assemblies of elements - e.g., beams, columns, windows, etc. - along with the explicit (i.e., nonparametric) 3D geometry of each element and some additional information such as material properties, building element classification or element versions. The AP has been developed as a German nationally funded project headed by W. Haas, and it is the furthest along in the standards process of the building construction AP's, having reached Committee Draft stage in January 1996. Experimental implementations have been completed that exchange complex building CAD models between heterogeneous CAD systems.

The major Units of Functionality (i.e., object groupings) defined in AP225 are listed as follows:

- building elements are the discrete, large-scale pieces of or things in the building

- building components correspond to individual shapes that make up an overall building element. For example, a column element may consist of 
a main cylinder component along with other additive components to form base and capital sections and subtractive components to form blockouts.

- the composition Units of Functionality (UoF) identifies buildings which decompose into building sections and levels. the building elements, which can be arranged into element assemblies, are positioned within these sections and levels.

- the design administration Units of Functionality (UoF) identifies information such as approvals, modifications, or acceptance of building elements.

- the properties and classification Units of Functionality (UoF) represents non-geometric element information such as material properties and classifications.

In addition, there are several geometry UoF's to describe specific shape representations (Katranuschkov and Scherer, 1996):.

- AP230 - Structural Frame: Steelwork. AP230 arose from a large European EUREKA project called CIMsteel. One of CIMsteel's goals was to advance information integration within the structural steel industry, a challenge met with the development of product models and integration prototypes. In 1994, the CIMsteel product model was promoted as a STEP AP project covering construction steelwork frame design, analysis and detailing, and fabrication. The development is lead by A. Watson and M. Ward of Leeds University.

- AP228 - Building Services: HVAC. AP228 focuses on heating, ventilation, and air conditioning building services. The project has drawn heavily from two European projects, JOULE COMBINE and ESPRIT ATLAS. The project is lead by P. Poyet and J. Monceyron of CSTB, France.

\section{A FRAMEWORK FOR DEVELOPING AN ICT INFRASTRUCTURE FOR CONSTRUCTION}

\section{1. - Generic description of the framework}

Grounded on the context described by the two previous chapters, we have developed a high-level framework which the overall objectives are the development of a information and communication management infrastructure, including standards (STEP and EDIFACT), to provide transport and transparent presentation of product data and business information in the multi-supplier, multisite environment of construction industry (Figure 1). The framework intents through the application on real cases to accelerate and enhance the ability of European construction industry to capitalise on the emergence of a powerful Information Infrastructure. 


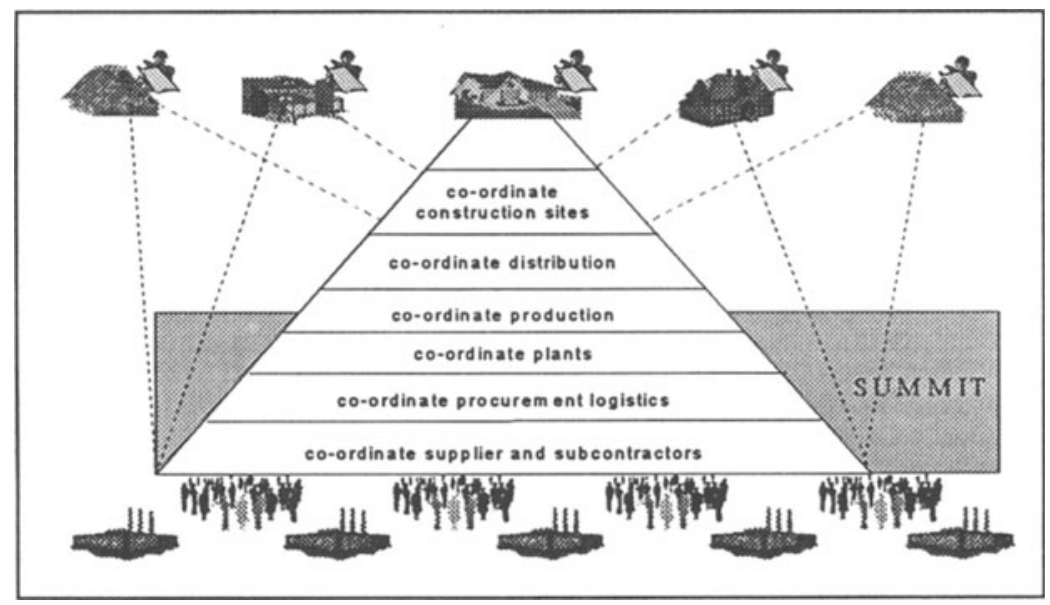

Figure 1: Multi-supplier, multi-site environment ICT infrastructure R\&D framework

The goal is to achieve an "information logistics" infrastructure providing the required data at every step of the business processes, to underpin the logistics of the supply and distribution of buildings and equipment. The framework considers that the building of an ICT infrastructure must be tailored with respect to the heterogeneous supply chain typical for construction industry, which involves partners of all company sizes and ICT-skill levels.

The development framework applications will focus on the commercial and architectural refinement business chains and will be primarily targeted at supporting the production process. It will be targeting the complete integration of product, process and business data for the above chains. The development of EDI, standard interfaces and inter-organisational information flow system will lead to a complete electronic working environment.

\section{2. - Technical objectives}

The technical objectives of the development framework are as follows:

Inter-organisational information flow system

- Supporting the co-ordination of distributed business processes in temporary architectural and production networks.

EDIFACT-message types for construction industry

- Defining construction and building specific EDIFACT messages respectively subsets for selected commercial business processes and engineering processes. 
- Contribute to the development of the Application Protocol for electronic exchange of Explicit Shape Representations.

\section{STEP and EDIFACT processor development}

- Developing an EDI environment to support the management of technical data and commercial data for the construction project business chains.

Integrated EDI, STEP-EDIFACT processors, and information flow system and application

- A prototype implementation of business chain scenarios for purchasing and architectural refinement.

\section{Implementation and demonstration}

- Implementing and demonstrating the applications developed, and resulting benefits through data exchange cases between firms based on real business scenarios.

\section{Dissemination and exploitation}

- Provide the applied R\&D results to the public especially to SMEs by establishing Supplier/Subcontractor forums.

Recently a consortium of four industrial firms and a research institute have started to apply this research and development framework into real cases. The results will be described elsewhere.

\section{3. - Business and industrial impact}

The development of EDI and ICT on construction virtual enterprises is expected to lead to important changes in its structure and organisation. Some of the factors that are perceived by some construction researchers as hindering the development of electronic information exchange are expected to change (Grilo et al, 1996).

Relationships. The relationships on construction industry are usually adversarial, committed to the project duration, and with low co-operation and collaboration. Following trends in other industries, with the deployment of electronic communications, it is envisaged that construction parties develop more trustful, long-term committed and collaborative relationships. The current project partnering trend is expected to be extended to strategic partnering.

Information Exchange. Due its complexity and uncertainty the information requirements of the construction industry are very high. However, due the usual contractual arrangements and the type of relationships, information sharing is restricted to operational levels and the strictly necessary to the completion of the projects. Moreover, the quality of the information is low. It is envisaged that the 
EDI/Email will facilitate more better information sharing and improve its timeliness, accuracy, adequacy, and transparency.

Process Innovation. Construction companies do not see procurement and logistics as core processes. There is a lack of believe that improvements on those processes may bring real project benefits. Moreover, it is stressed in the industry that benefits may only occur if radical changes are made.This applied research and development framework envisage to demonstrate that incremental changes on the procurement and logistics processes of the construction virtual enterprises enabled and supported by an IT infrastructure can provide real benefits to construction projects and firms.

Technology. There are very few ICT applications developed specifically to the construction virtual enterprises. As construction business processes have peculiarities when compared with manufacturing and service industries, it is important to develop not only tailored applications but also to construction specific ICT expertise.

\section{CONCLUSIONS}

Electronic exchange of information within construction virtual enterprises is seen as having a significant role in improving the productivity of construction processes. In order to achieve this we have presented a development framework which aims at exploiting the potentials of both the STEP and EDIFACT approaches to product and process data communication by a concept of combining the complementary nature (business versus engineering data) of both approaches. This, together with an EDI system based on a interorganisational information flow system, will facilitate the realisation of a virtual enterprise of smallest and largest companies. It is expected that an ICT infrastructure like the one described here will impact the relationhsips; information exchange; process innovation and technology of the construction industry.

\section{REFERENCES}

Akintoye, A. and McKellar, T. (1997), Electronic Data Interchange in the UK Construction Industry; RICS Research paper series, Volume 2, Number 4

Atkin, B. and Pothecary, E. (1994), Building Futures; University of Reading, Dept. of Construction Management and Engineering

Baldwin, A., Thorpe, A, and Carter, C. (1995), Data Exchange in Construction: EDI, MFE or IE? in Developments in Computational Techniques For Civil Engineering, pp 11-15, B.H.V Topping, Civil-Comp Press, Edinburgh, UK 
Cherns, A. and Bryant, D. (1983), Studying the Client's Role in Construction Management; Construction Management and Economics, 2 , ppl 17

DOE, (1995), Construct IT - Bridging the Gap, HMSO

Emmelhainz, M.A. (1993), Electronic Data Interchange, A Total Management Guide; Van Nostrand Reinhold International, London

Grilo, A., Betts, M. and Mateus, M. (1996), Electronic Interaction in Construction: Why Is It Not a Reality?; in CIB Proceedings of the Construction on The Information Highway, Bled, Slovenia

Katranuschkov, P. and Scherer, R.J. (1996), Schema mapping an object matching: a STEP-based approach to engineering data management in open integrated environments; in CIB Proceedings of the Construction on The Information Highway, Bled, Slovenia

Latham, Sir M. (1994); Constructing the Team; HMSO

Thorpe, A. and Murray, J.J (1996), COMPOSITE - Site Communications Survey; Loughborough University of Technology, unpublished report 